Viti iXII ${ }^{- \text {tè }}$ i Botimit, Nr.1-2,

Dhjetor 2020

\title{
ELEMENTE TË SIMBOLIKËS SË GJALLESAVE NË ARKITEKTURËN KRISTIANE TË KISHËS SË SHËN NIKOLLËS NË MANASTIRIN E MESOPOTAMIT
}

\author{
Laura Shumka* \\ *Departamenti i Art Dizajnit, Fakulteti i Shkencave të Aplikuara dhe Ekonomike, \\ Albanian University
}

Adresë kontakti: 1 .shumka@albanianuniversity.edu.al

\section{Përmbledhje}

Qëllimi i këtij artikulli është që të përshkruajë dhe analizojë përdorimin e simbolikës së gjallesave në arkitekturën kristiane të Kishës së Shën Nikollës në Manastirin e Mesopotamit, i cili përfaqëson një ndër monumentet më të spikaturura të kulturës shqiptare. Ky monument shquhet jo vetëm për karakteristikat e spikatura arkitektonike, por edhe për elementët e dekorimit që përfshijnë dyshemenë, kapitelet, skulpturat në muret e jashtme dhe simbolikat me shprehje të gjallesave shtazore dhe bimore. Simbolikat, në këtë kontekst shqiponja, si një simbol i lidershipit është aq e vjetër sa perënditë dhe dinastitë sunduese. Si një arketip ajo mund të përfaqësojë një hyjni të gjithë fuqishme, diellin (e njëjta gjë në shumë fe të lashta), fuqinë e papërpunuar, mbizotërimin, lirinë e lëvizjes, etj. Si shoqërues të shpeshtë të mundshëm paraqiten luani dhe gjarpri, ndërkohë që dragoi ndeshet në mjaft objekte. Potenciali i tyre është i qartë për këdo që ka një qasje imagjinate. Edhe në rastin e Kishës së Shën Nikollës në Mesopotam simbolet paraqiten si shprehje tejet e fuqishme e fasadës së monumetit.

Fjalë çelës: simbolika, Kisha e Shën Nikollës, Mesopotam, arkitekturë, monument

\section{LIVINGS SYMBOLISM IN ECCLESIASTICAL ARCHITECTURE OF ST. NOCO- LAS CHURCH OF THE MONASTERY IN MESOPOTAM}

\begin{abstract}
The purpose of this article is to describe the symbolism of living creatures used in the ecclesiastical architecture of the Church of St. Nicholas in the Monastery of Mesopotamia that represents one of the most prominent monuments of Albanian culture.
\end{abstract}


Laura Shumka

This monument is notable not only for its outstanding architectural features, but also for its decorative elements that include the floor, capitals, sculptures on the exterior walls and symbolism with expressions of animal and plant creatures. Symbols, particularly in this contexts, the eagle as a symbol of leadership is as old as gods, and ruling dynasties. As an archetype it can represent an all powerful deity, the sun (the same thing in many ancient religions), raw power, dominance, freedom of movement, etc.. The lion and the snake appear as frequent possible accompanying elements, while the dragon is encountered in almost as many objects. Their potential is clear to anyone who has an imaginative approach. Even in the case of St. Nicholas Church in Mesopotamia, the symbols appear as a very powerful expression of the facade of the monument.

Keywords: symbolism, St. Nicola Church, Mesopotam, architecture, monuments

\section{Hyrje}

Bazuar në gjendjen e objekteve të ndryshme të kultit dhe në publikime të ndryshme, mund të thuhet se arkitektuara bizantine dhe pasbizantine me numrin e saj të objekteve në një kohështrirje prej dhjetra shekujsh, përbën një nga fushat më interesante të kërkimit shkencor. Nga sa më sipër, kjo periudhë në të gjitha aspektet e saj kërkon studime të integruara si çdo periudhë tjetër apo tipizim arkitektonik. Pra ajo kërkon në aspektin e gjërë njohjen e tipave arkitektonike që u përdorën gjatë kësaj periudhe, ndryshimet që pësuan si pasojë e organizimit të hapësirës së brendshme, kompozimit të jashtëm, të teknikës së ndërtimit, të dekoracioneve etj.

Zhvillimi në kohë kërkon një ndjekje e cila duhet të verë në dukje tiparet e reja që ajo fitoi në zona të ndryshme të vendit tonë dhe të zbulohen larmitë në aspekte të ndryshme krahinore dhe kohore. Për fat të mirë akoma ruhen kisha pasbizantine, kryesisht në Shqipërinë e Jugut të cilat do të përbëjnë elementin bazë të analizës së studimit, i cili konsideron dyert dhe dritaret, stilet dhe tipologjitë e tyre si rrjedhë logjike e kontekstit të kohës dhe ndikimeve të periudhave të kaluara.

Në këtë kuadër, Kisha e Shën Nikollës e Manastirit në Mesopotam e cila mendohet të jetë ndërtuar në 1224 ose 1225 përbën një monument tejet të spikatur. Dikur ajo ishte rrethuar nga një mur rrethor i cili sot ruhet vetëm pjesërisht ${ }^{[1,2,3]}$. Ky ndërtim është një ndër monumentet tipike të arkitekturës bizantine ndër më të spikaturit në vendin tonë. Apsida e saj e dyfishtë e bën atë unike në zhanrin e saj, ndërkohë që disa studiues kanë përparuar hipotezën se kjo ishte për shkak të manastirit që po përdorej nga dy rite fetare (katolike dhe ortodokse). Skizma Lindje - Perëndim e vitit 1054 duket se nuk i ka penguar besimtarët katolikë dhe ortodoksë në Mesopotam, dukshëm i suksesshëm në gjetjen e një kompromisi që u mundësoi atyre të punonin së bashku në ndërtimin e manastirit [3]. 
ELEMENTE TË SIMBOLIKËS SË GJALLESAVE NË ARKITEKTURËN KRISTIANE TË KISHËS SË SHËN NIKOLLËS NË MANASTIRIN E MESOPOTAMIT

Ndër studiuesit e parë të këtij objekti përmendet Versaqis [4], i cili për herë të parë ka bërë përshkrimin e arkitekturës së kishës dhe të detajeve të tjera si sklupturat dhe anekset rrethuese. Me vonë Ugolini [5] përmend kishën në kontekstin e rrethinës dhe aspekteve arkeologjike të zonës.

Simbolika specifike e shprehur përmes shqiponjës, kafshëve mitologjike (dragoit), luanit në stile të ndryshme, qenit etj., janë trajtuar nga Meksi [1], ndërkohë që autori përmes analizës krahasuese shpreh mendime në lidhje me datimin e simbolikës dhe fuqinë e shprehjes së tyre. Në simbolikën klasike shprehja e karakteristikave të luanit është e ndryshme, kështu ai paraqitet si një simbol i Ringjalljes në arkitekturë[6], ndërkohë që shpesh herë bishat kanë një domethënie të dyfishtë, si p.sh. luani dhe ariu si lloje të Satanait apo diabolizimi i qenit etj. Nga ana tjetër në mjaft raste shqiponja paraqitet si një simbol i aspiratës shpirtërore dhe rigjenerimit të pagëzimit.

\section{Materiale dhe Metoda}

Vendndodhja e monumentit: Kisha e Shën Nikollës e Manastirit të Mesopotamit gjendet 15 km në verilindje të Sarandës dhe $3 \mathrm{~km}$ në lindje të Finiqit, në një kodër pranë fshatit Mesopotam. Nga kompleksi i manastirit aktualisht kanë mbetur kisha, një pjesë e konakëve, si dhe rrënoja të mureve rrethues. Kisha gjendet në një zonë me kulturë të lashtë siç është Finiqi $[7]$.
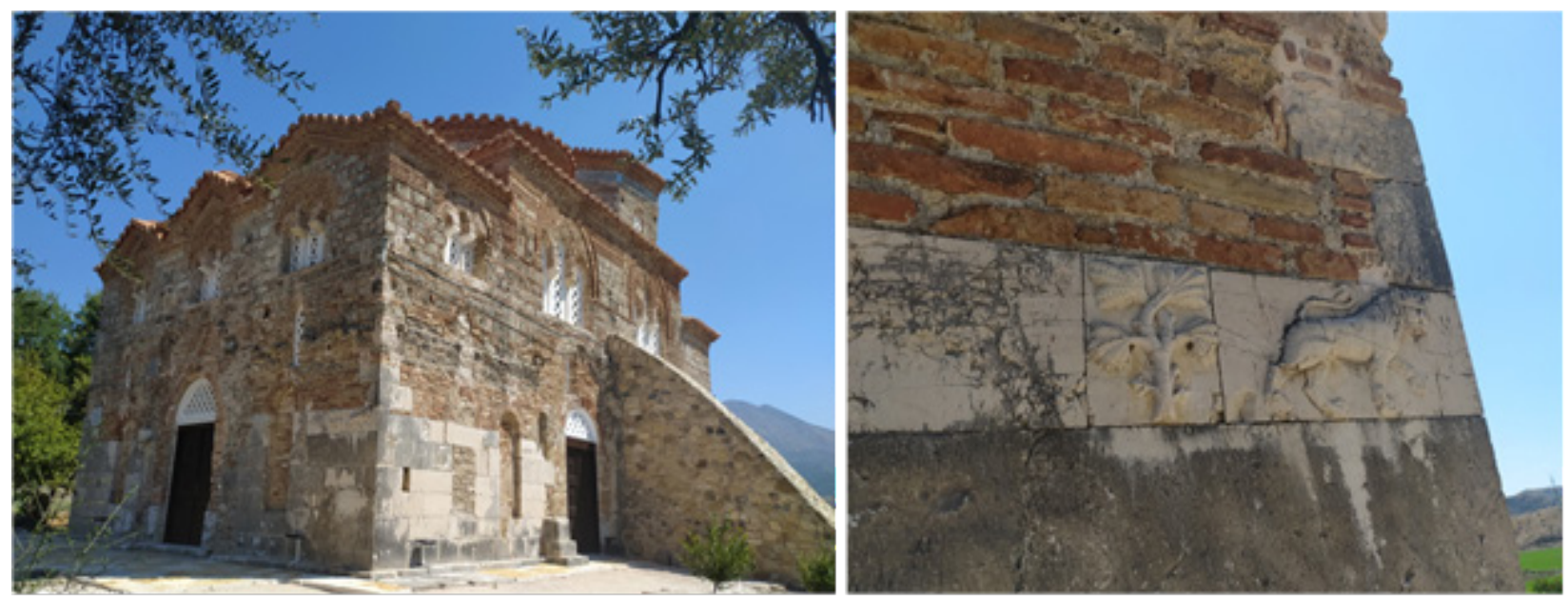

Figura 1. Pamje e jashtme e Kishës së Shën Nikollës - Manastiri i Mesopotamit 
Laura Shumka

Vizita në terren, fotografime dhe krahasime: gjatë periudhës së viteve 2017-2020 janë kryer tre vizita në terren me qëllim vlerësimin, dokumentimin dhe analizën e gjendjes së simboleve si pjesë e kompleksit arkitektonik të Kishës së Shën Nikollës - Manastiri i Mesopotamit. Simbolikat dhe detajet e lidhura me to, janë analizuar duke u bazuar në burime bibliografike vendase dhe të huaja.

\section{Rezultate dhe Diskutime}

Kisha e Shën Nikollës e Manastirit në Mesopotam mendohet të jetë ndërtuar në 1224 ose 1225. Dikur ajo ishte rrethuar nga një mur rrethor dhe është shpallur si Monument Kulture i Shqipërisë dhe është një vend i trashëgimisë së mbrojtur, megjithëse ndërtesa e kishës dhe tempullit së fundmi është shoqëruar me restaurim, i cili është i nevojshëm që të avancohet më tej duke e zgjeruar dhe zonën e rrethinës.

Sipas Gega [8] ky manastir është ndërtuar në muret e një tempulli shumë më të vjetër. Dëshmitë që ekipi kërkimor gjeti [8], përfshinin gurë helenë nga shekujt 3 - 4 pes, duke konfirmuar lidhjen me kryeqytetin e Lidhjes Epirote në Phoenice (Finiqi) që ndodhet $3 \mathrm{~km}$ nga manastiri. Një prej gurëve dekorativë mban mbishkrimin "Menelau”, supozohet të jetë një referencë për Mbretin Spartan Menelaus, vëllai i të cilit Agamemnon drejtoi sulmin gjatë Luftës së Trojës. Zona afër përfshin vendin antik të Butrintit për të cilin shkrimtari romak Virgil thotë se u themelua nga pasardhës trojanë të Priamit, të cilët u vendosën në zonë pas Luftës së Trojës [8]. Hapjet origjinale në muret e tempullit janë përdorur si kthina ose dritare nga ndërtuesit e manastirit. Një fotografi shoqëruese tregon një kthinë të tillë me një ikonë të Shën Nikollës, Shenjt mbrojtës të manastirit.

Bazuar në rezultatet kryesore të ekspeditave dhe studimeve të ndryshme [2] janë sqaruar forma planimetrike me dy apsida e portikë nga të tre anët, përcaktimi i mureve që i takojnë ndërtimit të parë dhe rindërtimeve të viteve 1792 dhe 1845. Ndërkohë që Meksi [2] trajton probleme të dekorit dhe në të njwjtën kohë shpreh opinionet origjinale duke i krahasuar me ato të studiuesve të tjerë. 
Tabela 1. Pozicionimi i simbolikave në Kishën e Shën Nikollës dhe shprehjet e tyre sipas autorëve të ndryshëm

\begin{tabular}{|c|c|c|c|}
\hline Nr. & Simboli & Pozicioni në ndërtesën e kishës & Simbolizimi (autori) \\
\hline 1 & Derr i egër & Muri verior, arkitrau i derës & $\begin{array}{l}\text { Derri i egër është një shenjë e bollëkut, } \\
\text { guximit dhe fuqisë, por që rastësisht } \\
\text { përfaqëson edhe kokëfortësi, konflikt } \\
\text { dhe çrregullim [9]. }\end{array}$ \\
\hline 2 & Qen (hijenë!) & Muri verior, arkitrau i derës & Simbolizim të satanait apo diabolizmit \\
\hline 3 & Shpend & Pjesa verilindore & I dëmtuar rëndë \\
\hline 4 & Shqiponjë & Muri lindor, brezi i poshtëm & $\begin{array}{l}\text { Simbol i aspiratës shpirtërore dhe rigje- } \\
\text { nerimit të pagëzimit [6];Shqiponja ës- } \\
\text { htë shpesh një simbol diellor dhe mund } \\
\text { të lidhet me të gjithë perënditë e qiellit. } \\
\text { Nënkupton frymëzimin, çlirimin nga skl- } \\
\text { lavëria, fitoren, jetëgjatësinë, shpejtës- } \\
\text { inë, krenarinë, dhe mbretërinë [9]. }\end{array}$ \\
\hline 5 & Dragua 1 & Muri lindor, brezi i poshtëm & $\begin{array}{l}\text { Dragoi është një simbol i së keqes. Në } \\
\text { Orient, ai simbolizon fuqinë e mbinatyr- } \\
\text { shme, mençurinë, forcën dhe njohurinë } \\
\text { e fshehur. Në shumicën e traditave, ai } \\
\text { është mishërimi i kaosit dhe natyrës së } \\
\text { patrembur [9]. }\end{array}$ \\
\hline 6 & Dragua 2 & Muri lindor, brezi i poshtëm & $\begin{array}{l}\text { Dragoi është një simbol i së keqes. Në } \\
\text { Orient, ai simbolizon fuqinë e mbinatyr- } \\
\text { shme, mençurinë, forcën dhe njohurinë } \\
\text { e fshehur. Në shumicën e traditave, ai } \\
\text { është mishërimi i kaosit dhe natyrës së } \\
\text { patrembur [9]. }\end{array}$ \\
\hline 7 & Luan 1 & Muri lindor, brezi i poshtëm & $\begin{array}{l}\text { Ringjallje [6]; Madhështia, forca, guxi- } \\
\text { mi, drejtësia dhe fuqia ushtarake [9]. }\end{array}$ \\
\hline 8 & Luan 2 & Fasada jugperëndimore & $\begin{array}{l}\text { Ringjallje [6]; Madhështia, forca, guxi- } \\
\text { mi, drejtësia dhe fuqia ushtarake [9]. }\end{array}$ \\
\hline
\end{tabular}



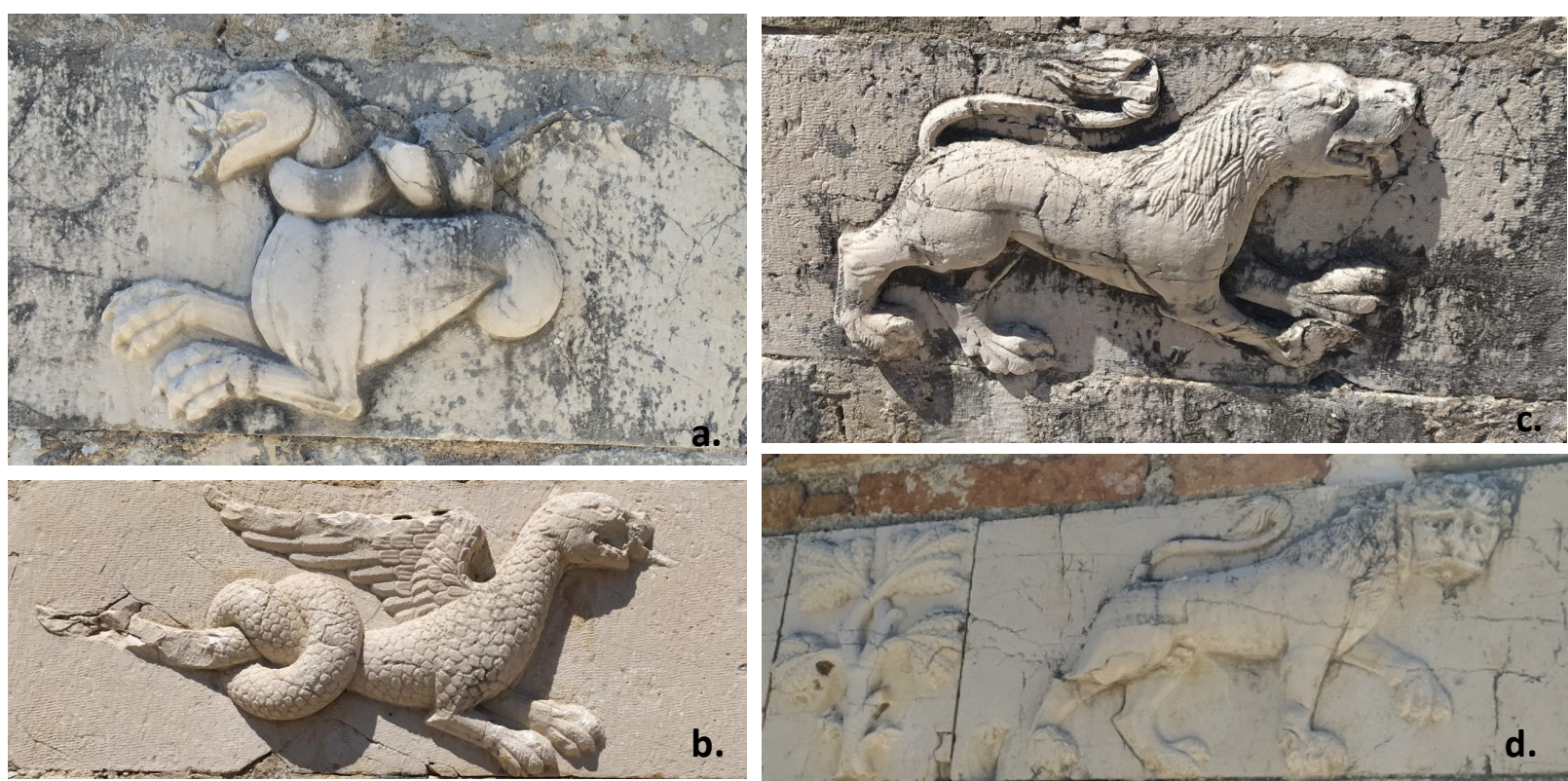

Figura 2. a. Simbol i dragoit me 'shall' dhe b. Simbol i dragoit me bishtin e përdredhur;

c. Simbol i luanit në pozicion sulmi dhe d. Simbol i luanit me kokë njeriu
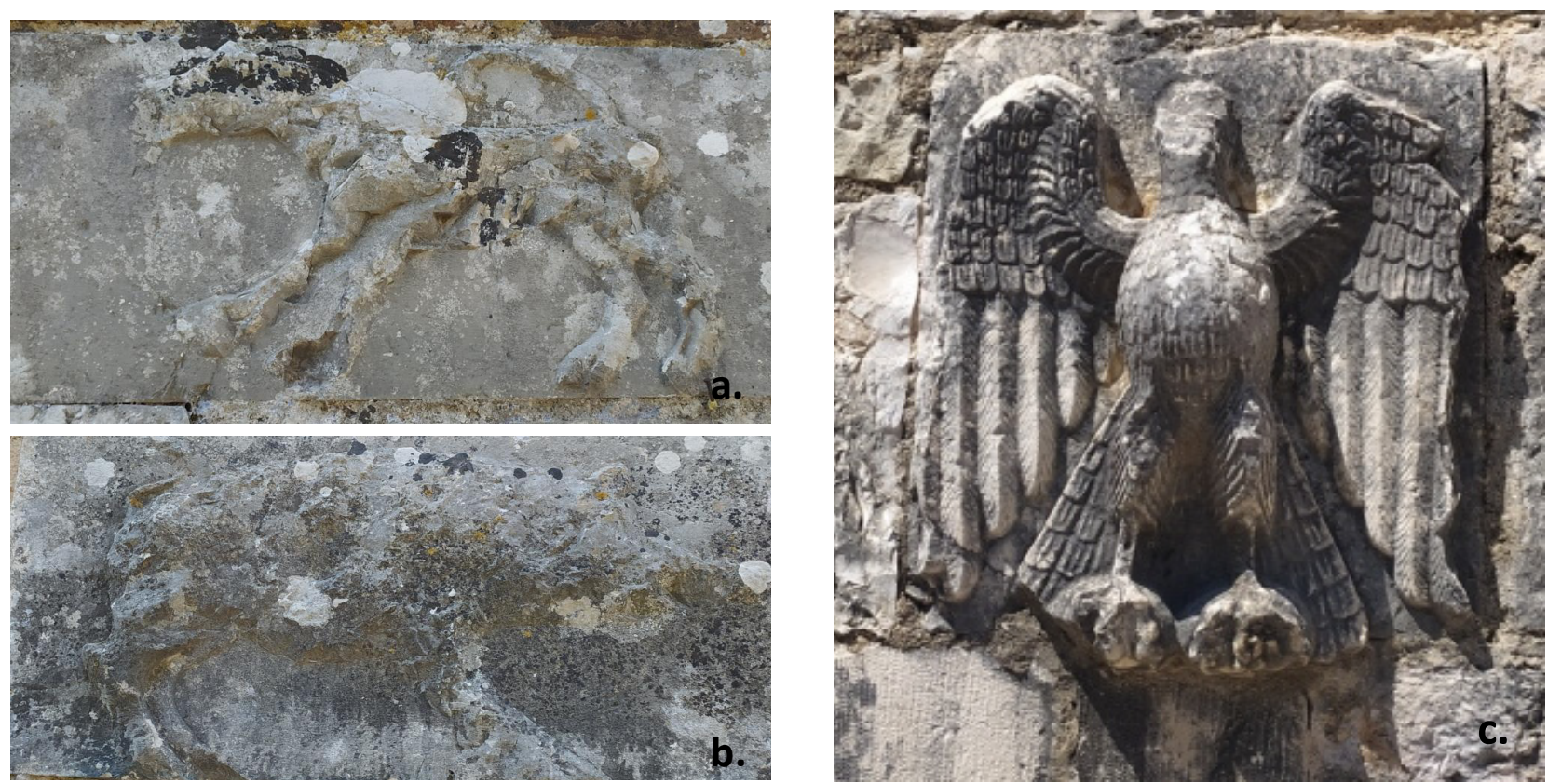

Figura 3. a. Simbol i qenit; b. Simbo i derrit të egër dhe c. Simbol shqiponjë një krenare 
ELEMENTE TË SIMBOLIKËS SË GJALLESAVE NË ARKITEKTURËN KRISTIANE TË KISHËS SË SHËN NIKOLLËS NË MANASTIRIN E MESOPOTAMIT

Nga analiza e kryer në Tabelën 1, vërehet se në mjaft raste ka dhe interpretime kontradiktore, ndërkohë që në tërësinë e tyre simbolet janë shprehje e gjendjeve të ndryshme dhe përforcojnë idenë e vlerave unikale që mbart në vetvete ky monument.

Sipas Meksit [1] është vështirë të jepet një përgjigje e saktë se kujt periudhe i përkasin punimet e simbolikave në fasadën e kishës. Ndërkohë që ato ndryshojnë nga niveli i tyre artistik dhe stili i realizimeve, disa prej tyre si shqiponja dhe luani janë tejet të arritura. Tashmë ekzistojnë mendime të ndryshme në lidhje me kohën e punimit të tyre. Sipas Ugolinit [5] skena e fasadës veriore i përket periudhës romake, ndërsa strukturat e tjera i përkasin artit bizantin. Nga ana tjetër Puzanova dhe Dhamo [10] mendojnë se këto elemente janë paleokristiane. Ashtu sikurse elementet e tjera të kishës, fasada, pjesa e jashtme dhe e brendshme e saj, edhe simbolikat kanë pësuar dëmtime serioze të shkaktuara nga ndikime të kohës, faktorë klimatikë $[11,12]$, por edhe nga mungesa e menaxhimit dhe mirëmbajtjes. Në këtë kuadër është e nevojshme që krahas punimeve restauruese të monumentit në tërësi, duhet të ndërrmeren masa edhe për restaurimin e simbolikave pasi integriteti i monumentit nuk mund të kuptohet pa to.

\section{Përfundime}

Kisha e Manastirit të Mesopotamit përbën një monument unikal, ndërkohë që simbolikat që e shoqërojnë përforcojnë zgjidhjen e ndërtimit të një objekti të spikatur për nga madhësia dhe arkitektura. Mënyra e përfshirjes së simbolikës është tejet organike dhe funksionale në kontekstin e kohës së ndërtimit.

Monumenti në tërësinë e tij përgjatë shekujve, si pjesa e jashtme dhe e brendshme e saj edhe simbolikat, kanë pësuar dëmtime serioze të shkaktuara nga faktorë klimatikë por edhe nga mungesa e mirëmbajtjes. Në këtë kuadër është e nevojshme që krahas punimeve restauruese të objektit në tërësi, duhet të ndërmerren masa edhe për restaurimin e simbolikave pasi integriteti i monumentit nuk mund të kuptohet pa to. 
Laura Shumka

\section{Referenca}

1. Meksi A. Arkitektura e kishës së Mesopotamit. Monumentet, 1972. Nr. 3: 47-94

2. Giakoumēs Geōrgios K.; Vlassas Grēgorēs; Hardy David A. (1996). Monuments of Orthodoxy in Albania. Doukas School. ISBN 9789607203090

3. Versaqis F. Visantiakos naos en Dhelvino. In "Arkeollogjikon Dheltion”, 2015. No. $1: 28-44$

4. Ugolini L. Albania Antica, Roma, Milano, 1927. 142-142

5. Evans P. Animal symbolism in ecclesiastical architecture with a bibliography and seventy-eight illustrations. London: W.Heinemann 1896. p.173

6. Bara V. To Dhelvino, Athinë, 1966,151-153

7. Gega R. Të dhëna të reja mbi arkitekturën e manastirit të Shën Kollit në Mesopotam / New Data on the Architecture of St. Nicholas Monastery at Mesopotam. 2012. Iliria 36: $297-341$

8. Biederman H. Dictionary of Symbolism: Cultural Icons and the Meanings Behind Them. New York: Meridian, 1994

9. Puzanova V., Dhamo Dh. Niekotorie pamjatniki monumentalnoj zhivopisi 13-14 V v Albanii. Studia Albanica, 1965. Nr. 2, 149

10. Shumka L. Comparison of indoor climate features following different climate guidelines in conservation examples of selected churches in Albania. 2019. International Journal Of Conservation Science. Volume 10, Issue 4: 623-630

11. Shumka L., Peri L., Lato E. The Needs for Determining Degradation Risks from Temperature and Relative Humidity of Post-Byzantine Church Indoor Environment. Journal of Environmental Management and Tourism. 2020. V. 11, N. 3: 601-606 